\title{
Sonochemical Deposition of Palladium Nanoparticles Onto the Surface of N-Doped Carbon Nanotubes: A Simplified One-Step Catalyst Production Method
}

\author{
Ádám Prekob ${ }^{1} \cdot$ Gábor Muránszky $^{1}$ - István Kocserha ${ }^{2} \cdot$ Béla Fiser $^{1,3} \cdot$ Ferenc Kristály $^{4} \cdot$ Gyula Halasi $^{5} \cdot$ Zoltán Kónya $^{5}$. \\ Béla Viskolcz ${ }^{1}$. László Vanyorek ${ }^{1}$
}

Received: 5 November 2019 / Accepted: 9 December 2019 / Published online: 23 December 2019

(c) The Author(s) 2019

\begin{abstract}
This work presents an easy, one-step procedure for catalyst preparation. A small fraction of palladium ions was reduced to Pd nanoparticles and deposited onto the surface of nitrogen-doped carbon nanotubes (N-BCNT) by acoustic cavitation using high-intensity ultrasound in aqueous phase, where N-BCNT served as a reducing agent. The formation of elemental palladium and palladium oxides were confirmed and the particle size is $<5 \mathrm{~nm}$. The catalytic activity of the synthesized Pd/N-BCNT catalyst was tested in nitrobenzene hydrogenation at four different temperature (273-323 K) and 20 bar pressure. The catalyst showed high activity despite the presence of palladium oxide forms, the conversion of nitrobenzene to aniline was $98 \%$ at $323 \mathrm{~K}$ temperature after $40 \mathrm{~min}$. The activation energy was $35.81 \mathrm{~kJ} / \mathrm{mol}$. At $303 \mathrm{~K}$ and $323 \mathrm{~K}$ temperature, $N$-methylaniline was formed as by-product in a small quantity $\left(8 \mathrm{mmol} / \mathrm{dm}^{3}\right)$. By decreasing the reaction temperature (at $273 \mathrm{~K}$ and $283 \mathrm{~K}$ ), the reaction rate was also lower, but it was favourable for aniline selectivity, and not formed $n$-methylaniline. All in all, $\mathrm{Pd} / \mathrm{N}-\mathrm{BCNT}$ catalyst was successfully produced by using a one-step sonochemical method, where further activation was not necessary as the catalytic system was applicable in nitrobenzene hydrogenation.
\end{abstract}

\section{Graphic Abstract}

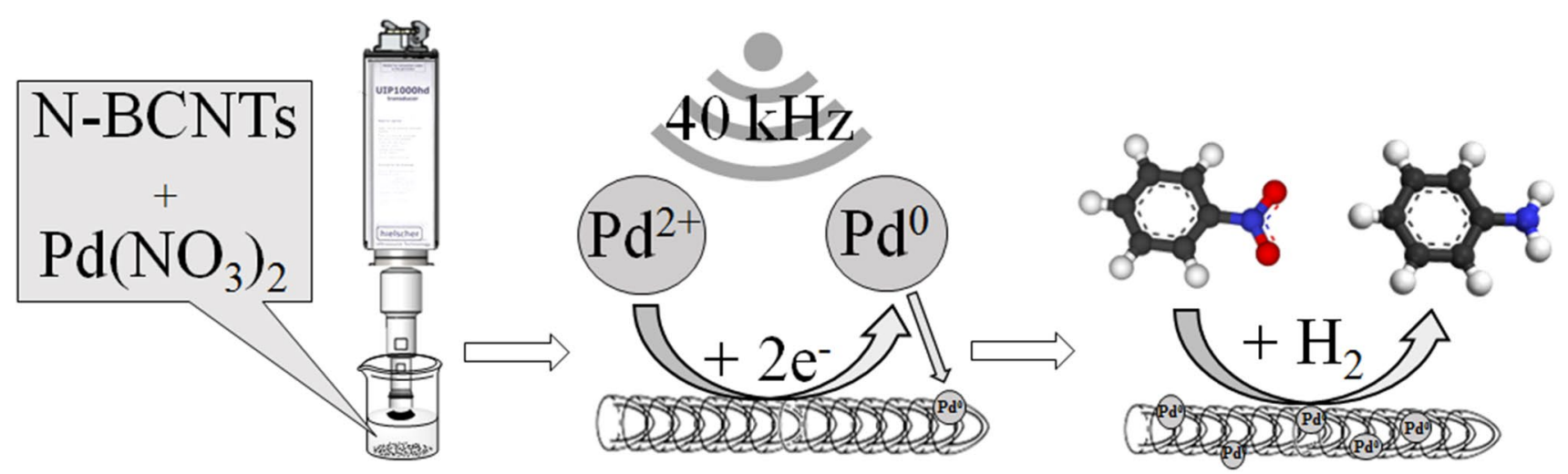

Keywords Ultrasound $\cdot \mathrm{N}-\mathrm{CNT} \cdot$ Nitrobenzene $\cdot$ Hydrogenation

\section{Introduction}

László Vanyorek

kemvanyi@uni-miskolc.hu

Extended author information available on the last page of the article
Aniline is a versatile organic compound intensively used in the chemical industry, and mainly applied in the production of polyurethane precursors. Several different procedures have been developed to synthesize aniline such as 
nitrobenzene reduction by iron in the presence of hydrochloric acid (Béchamp process) [1], phenol amination [2], and nitrobenzene hydrogenation [3-5]. The industrial production of aniline includes the latter, nitrobenzene hydrogenation, where a wide variety of catalysts can be used. Usually, the catalyst consists of a catalytically active metal (e.g. $\mathrm{Ni}, \mathrm{Pd}, \mathrm{Pt}, \mathrm{Cu}$ ) and a carrier or support (e.g. various carbon forms, alumina, silica, zeolites). $\mathrm{Pd}, \mathrm{Pt}, \mathrm{Ru}$, and $\mathrm{Rh}$ decorated catalysts with carbon $(\mathrm{C})$, silica $\left(\mathrm{SiO}_{2}\right)$ or alumina $\left(\mathrm{Al}_{2} \mathrm{O}_{3}\right)$ supports were compared in aniline synthesis [6]. The catalytic activity varied depending on the applied metal $(\mathrm{Pt}>\mathrm{Pd}>\mathrm{Ru}, \mathrm{Rh})$, and carriers $\left(\mathrm{C}>\mathrm{Al}_{2} \mathrm{O}_{3}, \mathrm{SiO}_{2}\right)$. Nanostructured carbon forms, mainly carbon nanotubes (CNTs) are the most widely applied and studied support materials, owing to their fascinating properties such as, extraordinary mechanical strength, good chemical stability and large surface area [7]. CNTs do not have micropores, thus, there is no mass transfer limitation during the catalytic processes which leads to higher reaction rates and better efficiency. Several studies have shown that a wide range of reactions including sorbitol hydrogenolysis to glycols, nitrocyclohexene hydrogenation, $\mathrm{CO}_{2}$ reduction, Fischer-Tropsch and aniline synthesis can be successfully catalysed by using CNT-based catalysts with different metals $(\mathrm{Pd}, \mathrm{Pt}, \mathrm{Ru}, \mathrm{Ni})$ [6, 8-17]. The characteristics of carbon nanotubes can be further finetuned by incorporating heteroatoms into their structure [18]. Such incorporation can be done by using nitrogen containing carbon compounds as starting materials for the synthesis of CNTs, which will induce the formation of nitrogen-doped bamboo-like carbon nanotubes (N-BCNT) [19]. N-BCNTs have more defect sites than their single- or multi-walled counterparts, and due to the incorporated nitrogen atoms, they also have special adsorption points which are excellent spots for catalytically active metal particles [20,21].

In several cases, the catalyst preparation procedures included an activation step, within which the metal-ions, -oxides and -complex ions were reduced by hydrogen gas to a catalytically active form, a metallic phase. However, the activation step is time and energy consuming. A viable alternative for metal nanoparticle production is applying acoustic cavitation. By using high-intensity ultrasound treatment, the formation of vapour microbubbles can be induced in metal ion solutions. Then, these bubbles will collapse and this leads to intense local heating $(\sim 5000 \mathrm{~K})$, high pressure $(\sim 1000 \mathrm{~atm})$, enormous heating and cooling rates $(>109 \mathrm{~K} / \mathrm{s})$ and liquid jet streams $(\sim 400 \mathrm{~km} / \mathrm{h})$ within small volumes, which are the so-called "hot spots" [22]. The energy in the "hot spots" can cover the needs of chemical reactions such as the reduction of metal ions to metals (e.g. $\mathrm{Au}, \mathrm{Co}, \mathrm{Fe}, \mathrm{Pd}, \mathrm{Ni}, \mathrm{Au} / \mathrm{Pd}$ and $\mathrm{Fe} / \mathrm{Co}$ ) in the presence of a reducing agent [23-28]. In our work, a one-step sonochemical catalyst preparation method is developed which does not require any post-treatment in order to activate the catalyst. The reducing agent in this redox process is the catalyst support itself, which is N-BCNT in this case, and it is oxidized during the reduction of the $\mathrm{Pd}^{2+}$ ions. The overall procedure will lead to the deposition of elemental palladium, palladium(II) oxide and palladium(IV) oxide particles onto the surface of the N-BCNT support.

\section{Materials and Methods}

N-BCNT synthesis was carried out by using a CCVD method [19]. To achieve the catalytic system, the synthesized $\mathrm{N}$-BCNT supports were decorated with palladium starting from palladium (II) nitrate dihydrate $\left(\mathrm{Pd}\left(\mathrm{NO}_{3}\right)_{2} \cdot 2 \mathrm{H}_{2} \mathrm{O}\right.$, Merck). Palladium nitrate dihydrate as Pd precursor $(0.20 \mathrm{~g})$ was solved in $1000 \mathrm{ml}$ distilled water, and $1.00 \mathrm{~g} \mathrm{~N}-\mathrm{BCNT}$ was added to the solution. The aqueous dispersion was sonicated by a Hielscher Ultrasound tip (UIP1000 HdT) homogenizer $(78 \mathrm{~W})$ for $10 \mathrm{~min}$. After the sonication and an additional 30 min contact time, the dispersion was filtered, and the Pd contained nanotubes were dried at $120^{\circ} \mathrm{C}$ overnight.

The final palladium nanocomposite catalyst was tested in nitrobenzene (Sigma Aldrich) hydrogenation. To identify the products analytical standards (Dr. Ehrenstorfer) such as aniline, nitrobenzene, nitrosobenzene and $N$-methylaniline were used.

The catalyst was examined (morphology, particle size and structure of the palladium nanoparticles) by high-resolution transmission electron microscopy (HRTEM, FEI Technai G2 electron microscope, $200 \mathrm{kV}$ ). The specimens were prepared by dropping aqueous suspension of the samples on 300 mesh copper grids (Ted Pella Inc.).

$\mathrm{X}$-ray diffraction (XRD) measurements were carried out by Bruker D8 Advance diffractometer (Cu-Ko source, $40 \mathrm{kV}$ and $40 \mathrm{~mA}$ ) in parallel beam geometry (Göbel mirror) with Vantec 1 detector to identify and quantify the crystalline phases of the palladium.

Functional groups on the surface of the nanotube support were studied by using Fourier-transform infrared spectroscopy (FTIR, Bruker Vertex 70 spectrometer).

The incorporated nitrogen forms and the oxidation states of the palladium were studied by X-ray photoelectron spectroscopy with a SPECS instrument applying equipped with a Phoibous $150 \mathrm{MCD}$ nine analyser. The $\mathrm{Al} \mathrm{K \alpha} \mathrm{x}$-ray source was operated at $14 \mathrm{kV}$ and $10.8 \mathrm{~mA}(150 \mathrm{~W})$. The analyser was operated FAT mode with a pass energy of $20 \mathrm{eV}$. High resolution spectra were acquired by averaging of 15 spectra of each region. CasaXPS software was used for data evaluation. The binding scale was to set so that the adventitious carbon C1s peak is at $284.8 \mathrm{eV}$.

The hydrogenation of nitrobenzene was carried out in a Büchi Uster Picoclave reactor system. The pressure of hydrogenation was 20 bar, the reaction temperature was set to 
$283 \mathrm{~K}, 293 \mathrm{~K}, 303 \mathrm{~K}$ and $313 \mathrm{~K}$, while the rotational speed was $1000 \mathrm{rpm}$. Sampling took place after the beginning of the reaction at $0,5,10,15,20,30,40,60,80,120,180$, and $240 \mathrm{~min}$. The hydrogenation process was followed by Agilent 7890A gas chromatograph coupled with Agilent 5975C Mass Selective detector. The separation was performed on a RTX-624 column $(60 \mathrm{~m} \times 0.25 \mathrm{~mm} \times 1.4 \mu \mathrm{m})$. The injected sample volume was $1 \mu \mathrm{L}$ at 200:1 split ratio, while the inlet temperature was set to $473 \mathrm{~K}$. The carrier gas was helium with constant flow $(2.28 \mathrm{~mL} / \mathrm{min})$, and the oven temperature was set to $323 \mathrm{~K}$ for $3 \mathrm{~min}$ and it was heated up to $523 \mathrm{~K}$ with $10 \mathrm{~K} /$ min increments and kept there for another $3 \mathrm{~min}$.

The efficiency of the catalytic hydrogenation was studied by calculating the conversion, $\mathrm{X} \%$ of nitrobenzene based on the following equation (Eq. 1):

$X \%=\frac{\text { consumed } n_{\text {nitrobenzene }}}{\text { initial } n_{\text {nitrobenzene }}} \times 100$

By assuming that the process is a first-order reaction [29-31]. Based on the initial and measured nitrobenzene concentrations $\left(\mathrm{c}_{0}\right.$ and $\left.\mathrm{c}_{\mathrm{k}}, \mathrm{mol} / \mathrm{dm}^{3}\right)$, the reaction rate constant $(\mathrm{k})$ was calculated at different temperatures by non-linear regression according to the following (Eq. 2):

$c_{k}=c_{0} \cdot \exp (-k \cdot t)$

\section{Results and Discussion}

\subsection{Characterization of the N-Doped Carbon Nanotube Supported Palladium Catalyst}

The deconvoluted XRD pattern confirmed that the total amount of palladium nitrate has been reduced to palladium oxide ( $\mathrm{PdO}$ and $\mathrm{PdO}_{2}$ ) and elemental palladium (Fig. 1). The (101) and (112) reflexions of palladium(II) oxide have been identified at $33.3^{\circ}$ and $53.7^{\circ}$ two theta degrees on the diffractogram. The peaks at $27.2^{\circ}$ and $54.7^{\circ}$ two theta degrees were assigned to the (110) and (211) reflexions of the palladium(IV) oxide. The reflexions of the $\mathrm{Pd}(111)$ and $\operatorname{Pd}(200)$ are found in strong preferred orientation at $40.5^{\circ}$ and $47.1^{\circ}$ two theta degrees. The presence of elemental nickel and $\mathrm{MgO}$ have also been confirmed, which is due to the fact that nickel containing $\mathrm{MgO}$ catalyst was applied to synthesize the N-BCNT and in small quantities remained in the system afterwards.

The FTIR spectra of the pristine and the Pd decorated carbon nanotubes have been measured (Fig. 2). The absorbance at $1099 \mathrm{~cm}^{-1}$ indicates the presence of incorporated nitrogen atoms. The stretching vibration mode of the $\mathrm{C}-\mathrm{O}$ bonds is found at $1239 \mathrm{~cm}^{-1}$. Peaks originated from the CNT structure can be found at $1631 \mathrm{~cm}^{-1}, 2897 \mathrm{~cm}^{-1}$ and $2938 \mathrm{~cm}^{-1}$ wavenumbers, which are corresponds to the $\mathrm{C}=\mathrm{C}$, and the symmetric and asymmetric $\mathrm{C}-\mathrm{H}$ stretching vibrations, respectively. The band of the surface hydroxyl groups can be found at $3448 \mathrm{~cm}^{-1}$, which includes the peaks of amine groups $(\nu \mathrm{NH})$ as well.
Fig. 1 Deconvoluted XRD pattern of the synthesized $\mathrm{Pd} / \mathrm{N}$ BCNT catalyst

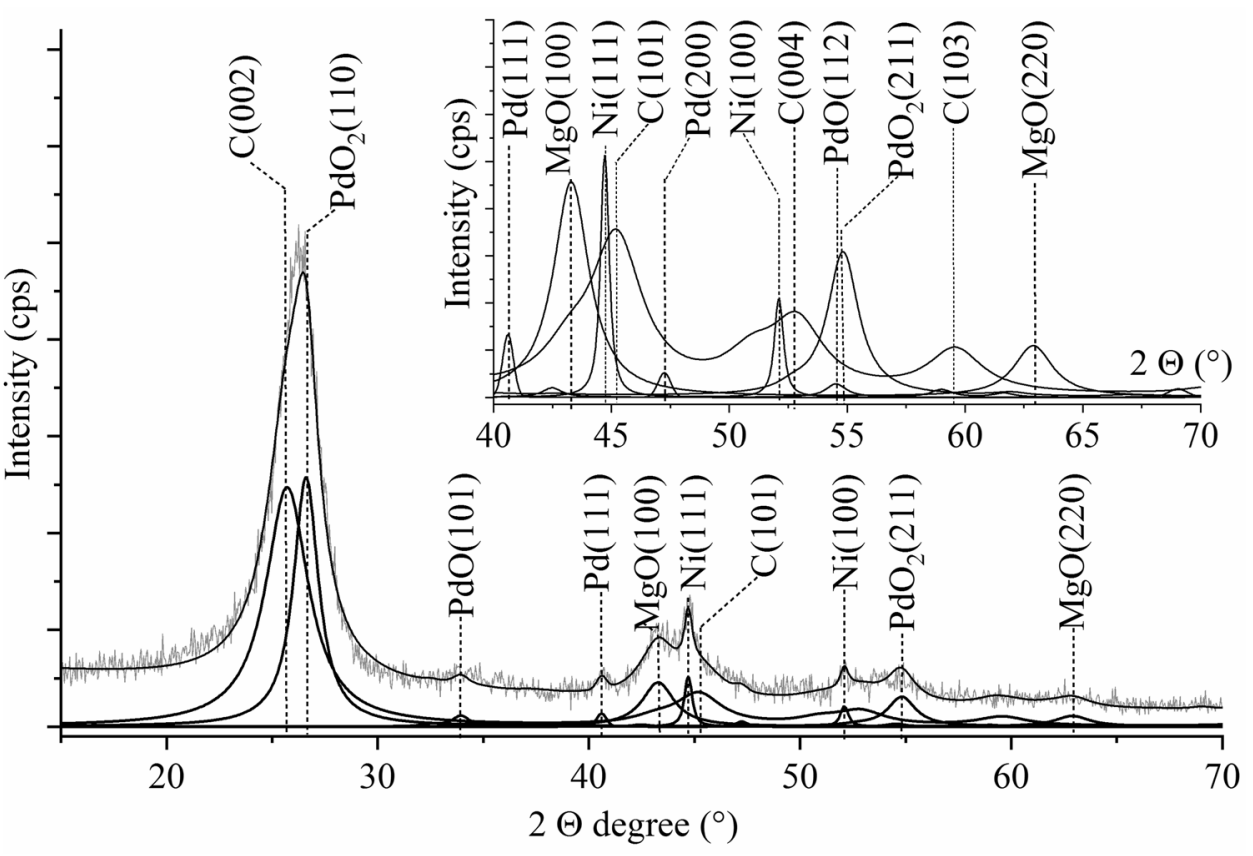




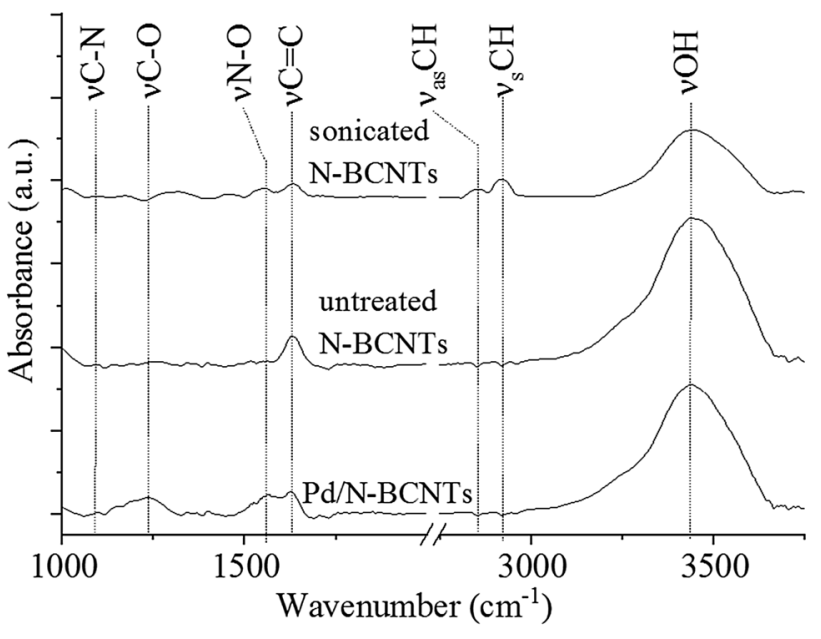

Fig. 2 FTIR spectra of sonicated and untreated N-BCNT and Pd/NBCNT
The stretching vibration mode of the $\mathrm{N}-\mathrm{O}$ bond only appeared in the spectrum of the $\mathrm{Pd} / \mathrm{N}-\mathrm{BCNT}$ sample (Fig. 2). The presence of $\iota \mathrm{NO}$ originated from the palladium precursor $\left(\mathrm{Pd}\left(\mathrm{NO}_{3}\right)_{2}\right)$. During the reduction of palladium ions, carbon atoms were oxidized, which can be confirmed by the appearance of the intensive band at $1244 \mathrm{~cm}^{-1}$ which was identified as the $\nu \mathrm{C}-\mathrm{O}$ stretching. It can also be observed that the absorption band of the $-\mathrm{COOH}$ groups around $1720 \mathrm{~cm}^{-1}$ cannot be found in the case of $\mathrm{Pd} / \mathrm{N}$ BCNT. Control experiment with N-BCNTs was carried out without the addition of $\mathrm{Pd}^{2+}$ ions under the same ultrasonic condition for comparison. The $\mathrm{C}-\mathrm{O}$ band was not appeared in this case which means that, the oxidation of the N-BCNTs induced by the redox reaction which takes place between the palladium ions and nanotubes.

The N-BCNT samples were measured by XPS before and after the palladium decoration and the spectra are similar to each other regardless of the presence of Pd in the system. (Fig. 3). However, differences in the intensities of the peaks could be observed between the Pd free and Pd containing
Fig. 3 N1s band and O1s band of N-BCNT $(\mathbf{a}, \mathbf{b})$ and the $\mathrm{Pd} / \mathrm{N}-\mathrm{BCNT}$ catalyst $(\mathbf{c}, \mathbf{d})$, respectively
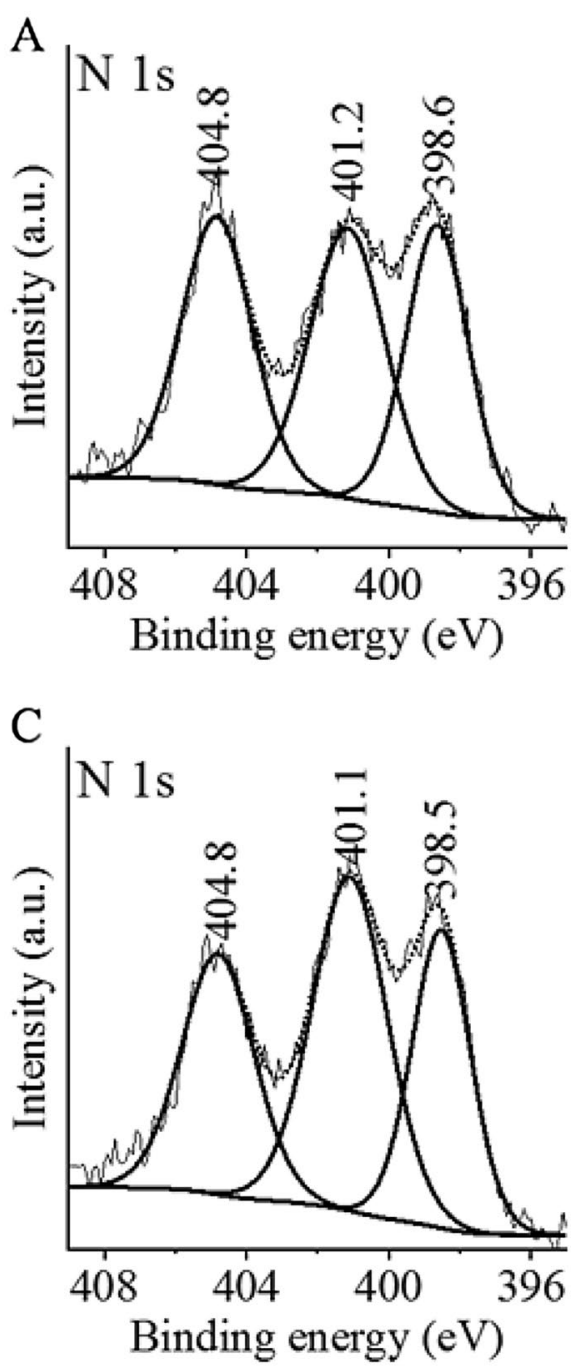
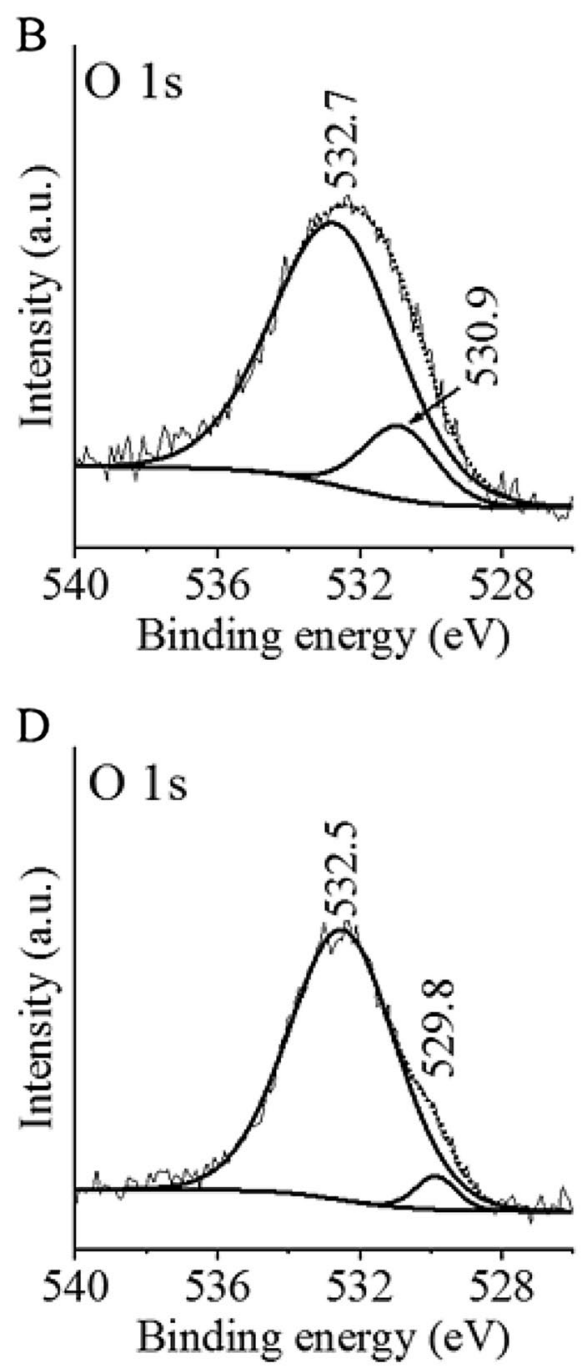
samples. On the deconvoluted N1s band three peaks were identified at $404.8 \mathrm{eV}, 401.2$ (401.1) eV and 398.6 (398.5) $\mathrm{eV}$ binding energy which are attributed to the oxidized pyridinic $\mathrm{N}$ atoms (pyridine oxide), quaternary and pyridinic nitrogen atoms, respectively (Fig. 3a, c). On the deconvoluted $\mathrm{O} 1 \mathrm{~s}$ band two peaks were located, the main peak can be attributed to the presence of surface hydroxides (Fig. 3b). In both cases a minor peak at lower binding energies was also observed which judging from its binding energy can be assigned to carbon-bound oxygen in the Pd free case and to palladium oxide in the decorated sample (Fig. 3d).

The ratio of the different nitrogen species has been changed by the Pd deposition (Table 1). The percentage of pyridinic $\mathrm{N}$ and the oxidized nitrogen species were decreased from 31.2 to $29.1 \%$ and 33.1 to $29.0 \%$ in case of the Pd/N-BCNT, respectively (Table 1). The decreased amount of pyridine $\mathrm{N}$-oxide could be explained by a palladium catalysed deoxygenation process [32]. However, the percentage of the quaternary $\mathrm{N}$ increased from 35.7 to $41.9 \%$ after the Pd deposition.

Peaks are assigned to elemental palladium, $\mathrm{PdO}$ and $\mathrm{PdO}_{2}$ in the XPS spectrum of the synthesized Pd/N-BCNT catalyst samples (Fig. 4). The presence of elemental palladium and

Table 1 Quantity of the different nitrogen forms in the N-BCNTs and the $\mathrm{Pd} / \mathrm{N}-\mathrm{BCNTs}$

\begin{tabular}{llll}
\hline Sample & \multicolumn{3}{l}{ Atomic percentage of nitrogen (\%) } \\
\cline { 2 - 4 } & Pyridinic N & Quaternary N & $\mathrm{N}-\mathrm{O}_{\mathrm{x}}$ species \\
\hline N-BCNT & 31.2 & 35.7 & 33.1 \\
Pd/N-BCNT & 29.1 & 41.9 & 29.0 \\
\hline
\end{tabular}

PdO have been indicated by two pair of bands at $[340.7 \mathrm{eV}$, $332.2 \mathrm{eV}]$ and $[342.5 \mathrm{eV}, 337.3 \mathrm{eV}]$, respectively. However, these peaks are slightly shifted compare to the literature values, which can be explained by the small particle size in case of $\mathrm{Pd}(<5 \mathrm{~nm})$ [33], and by the interaction with the catalyst support in case the PdO [34, 35]. Palladium(IV) oxide was also detected in the sample, and the corresponding bands are located at $343.6 \mathrm{eV}$ and $338.4 \mathrm{eV}$ binding energies.

The atomic percentage of the palladium forms were calculated with respect to the total palladium content of the $\mathrm{Pd} / \mathrm{N}-\mathrm{BCNTs}$ catalyst and it was found that $6.0 \% \mathrm{Pd}$ and $47 \% \mathrm{PdO}$ and $47 \% \mathrm{PdO}_{2}$ are present in the system. The total palladium content of the catalyst is $0.28 \%$ (atomic percentage), which is $2.5 \mathrm{wt} \%$ (percentage by weight). The $\mathrm{C}, \mathrm{N}$ and $\mathrm{O}$ contents are not differ significantly between the samples (Table 2).

The palladium nanoparticles are smaller than $5 \mathrm{~nm}$ according to the HRTEM images (Fig. 5). The dispersibility of the $\mathrm{Pd}$ and $\mathrm{PdO} / \mathrm{PdO}_{2}$ nanoparticles is high.

Table 2 Atomic percentages of the elements in the N-BCNT and $\mathrm{Pd} / \mathrm{N}-\mathrm{BCNT}$ sample

\begin{tabular}{lllll}
\hline Sample & \multicolumn{4}{l}{ Total Atomic percentage (\%) } \\
\cline { 2 - 5 } & C1s & N1s & O1s & Pd 3d \\
\hline N-BCNT & 94.0 & 3.2 & 2.8 & - \\
N-BCNT Pd & 93.4 & 3.5 & 2.8 & 0.3 \\
\hline
\end{tabular}

Fig. 4 Deconvoluted Pd 3d band of the Pd/N-BCNT catalyst

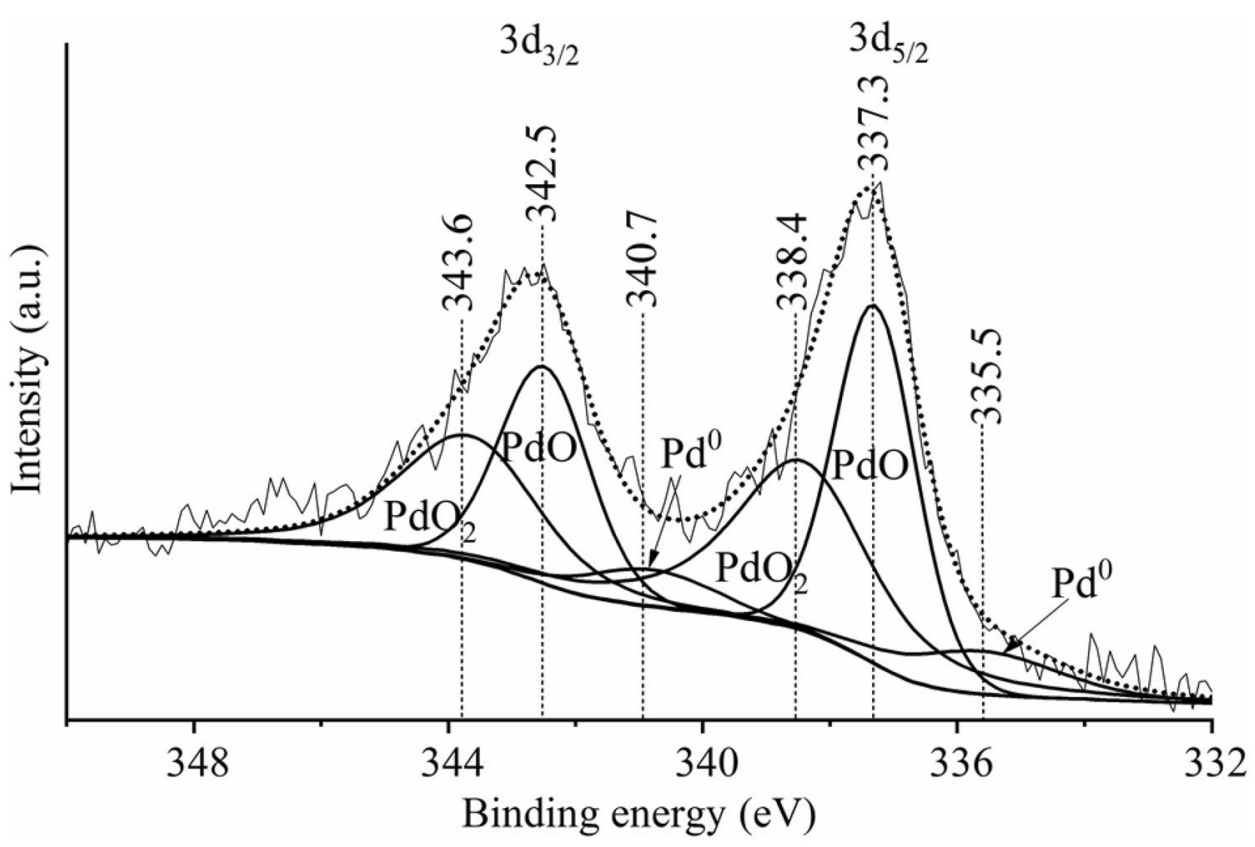



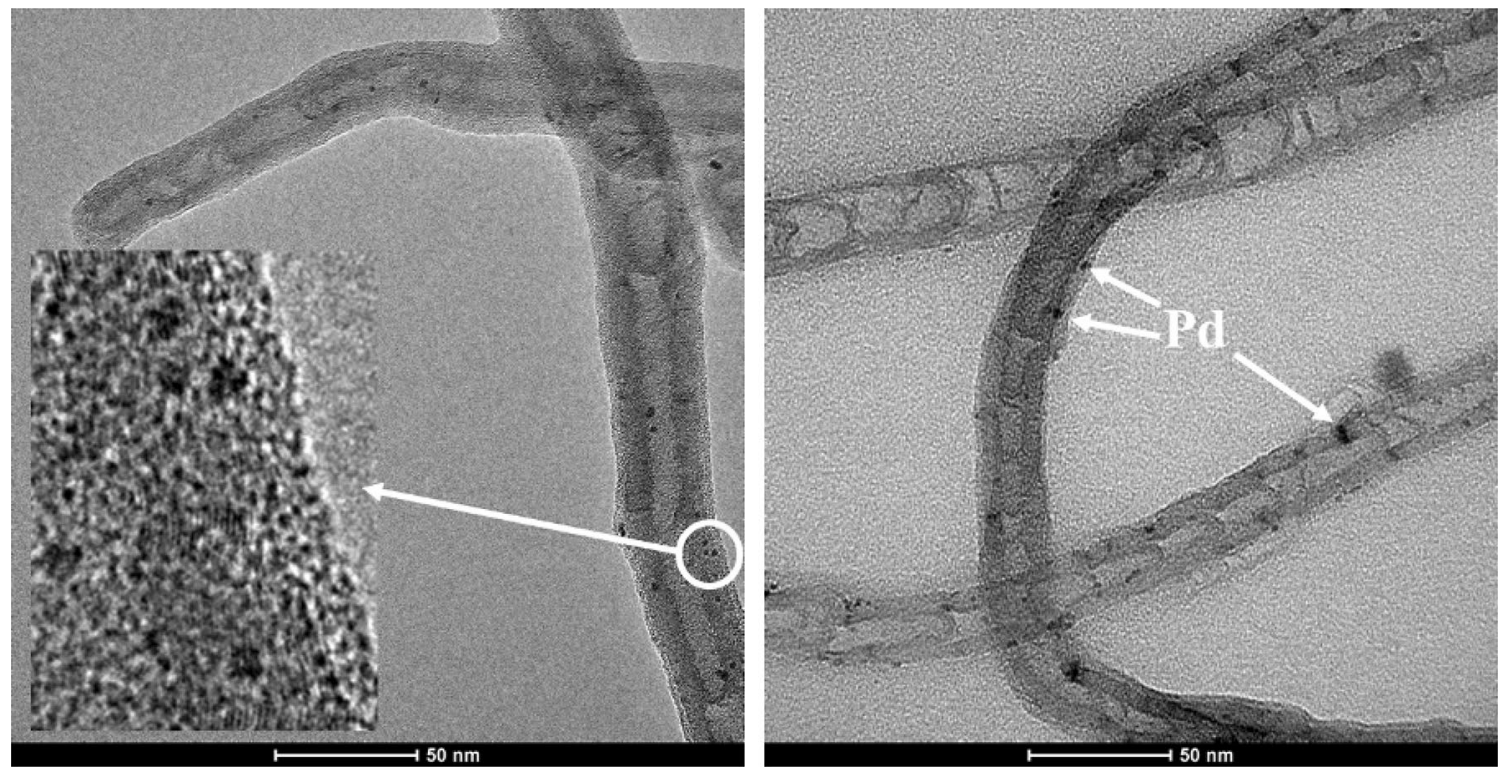

Fig. 5 HRTEM images of the Pd/N-BCNT catalyst

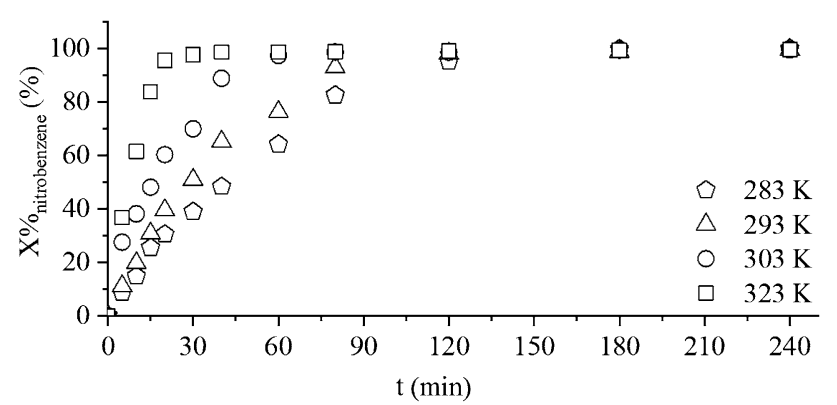

Fig. 6 Nitrobenzene conversion (X\%) vs time of hydrogenation

\subsection{Catalytic Tests of the Pd/N-BCNT Catalyst in Nitrobenzene Hydrogenation}

The synthesized $\mathrm{Pd} / \mathrm{N}-\mathrm{BCNT}$ catalyst was very efficient in each experiments, and the nitrobenzene conversion reached the maximum regardless the reaction temperature (Fig. 6). There is evidence in the literature, where the Pd oxide containing catalyst was more active, than the corresponding system which include only the metallic phase of palladium [36]. By increasing the reaction temperature, the reaction rate was also increased, at $323 \mathrm{~K}$ the conversion of nitrobenzene was $98.6 \%$, while at $283 \mathrm{~K}$ the conversion was $48.3 \%$ after 40 min hydrogenation.

Intermediates (nitrosobenzene and azoxybenzene) and a by-product ( $N$-methylaniline) have also been identified besides aniline (Fig. 7). The conversion of azoxybenzene to aniline is a fast process, which was detected only at lower temperatures ( $283 \mathrm{~K}$ and $293 \mathrm{~K}$ ), where the reaction was slower. The hydrogenation of nitrosobenzene intermediate to aniline was enhanced by increasing the reaction temperature. Only one by-product was formed at higher temperature $(303 \mathrm{~K}$ and $323 \mathrm{~K}$ ) values, $N$-methylaniline in a small concentration $\left(<8 \mathrm{mmol} / \mathrm{dm}^{3}\right)$. By decreasing the reaction temperature, the reaction rate was also lower, but it was favourable for aniline selectivity and $N$-methylaniline was not formed.

Based on the nitrobenzene concentration of the samples, the reaction rate constants $(\mathrm{k})$ at different temperatures were calculated (Table 3 ) by using a non-linear regression method (Fig. 8a) [37].

By applying the natural logarithm of reaction rate constants, the activation energy was also calculated using the Arrhenius plot. The (k) constants were plotted as a function of the temperature, and the activation energy can be calculated (Fig. 8b). The activation energy was $35.81 \mathrm{~kJ} / \mathrm{mol}$ which is similar to other Pd, Pt or Ru containing catalysts [38-41].

\section{Conclusion}

A one-step catalyst preparation procedure has been successfully developed. A small fraction of palladium ions was reduced to Pd nanoparticles and deposited onto the surface of nitrogen-doped carbon nanotubes (N-BCNT) by acoustic cavitation using high-intensity ultrasound in aqueous phase, where N-BCNT served as a reducing agent. The overall procedure will lead to the deposition of elemental palladium, palladium(II) oxide and palladium(IV) oxide particles onto 


\section{$\circ$ Nitrosobenzene $\Delta$ Azoxybenzene $\quad$ N-methylaniline}
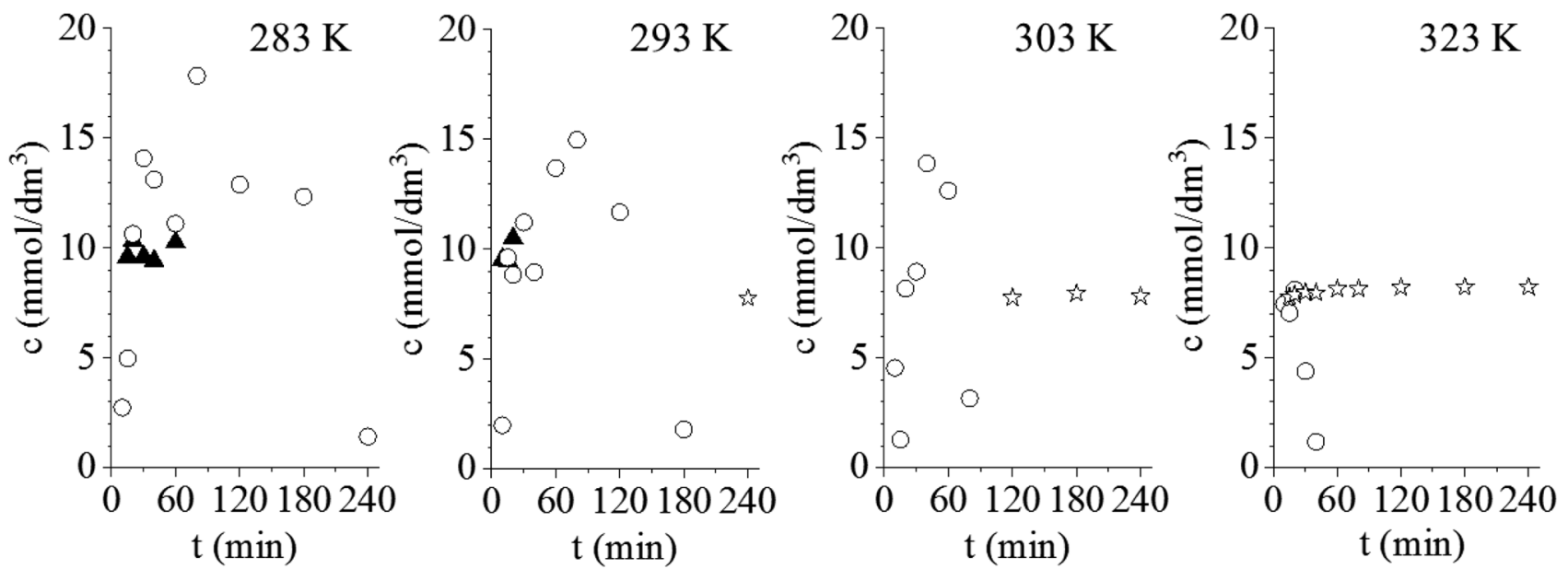

Fig. 7 Concentration of the intermediates and by-product $v s$ time of hydrogenation at different temperature values

Table 3 Reaction rate constants at different temperatures

\begin{tabular}{lllll}
\hline Temperature $(\mathrm{K})$ & 283 & 293 & 303 & 323 \\
\hline Reaction rate constant $\left(\mathrm{s}^{-1}\right)$ & $3.16 \times 10^{-1}$ & $4.35 \times 10^{-1}$ & $7.63 \times 10^{-1}$ & 1.84 \\
$\mathrm{SD}$ & $1.68 \times 10^{-2}$ & $1.67 \times 10^{-2}$ & $4.17 \times 10^{-2}$ & $1.07 \times 10^{-1}$ \\
\hline
\end{tabular}
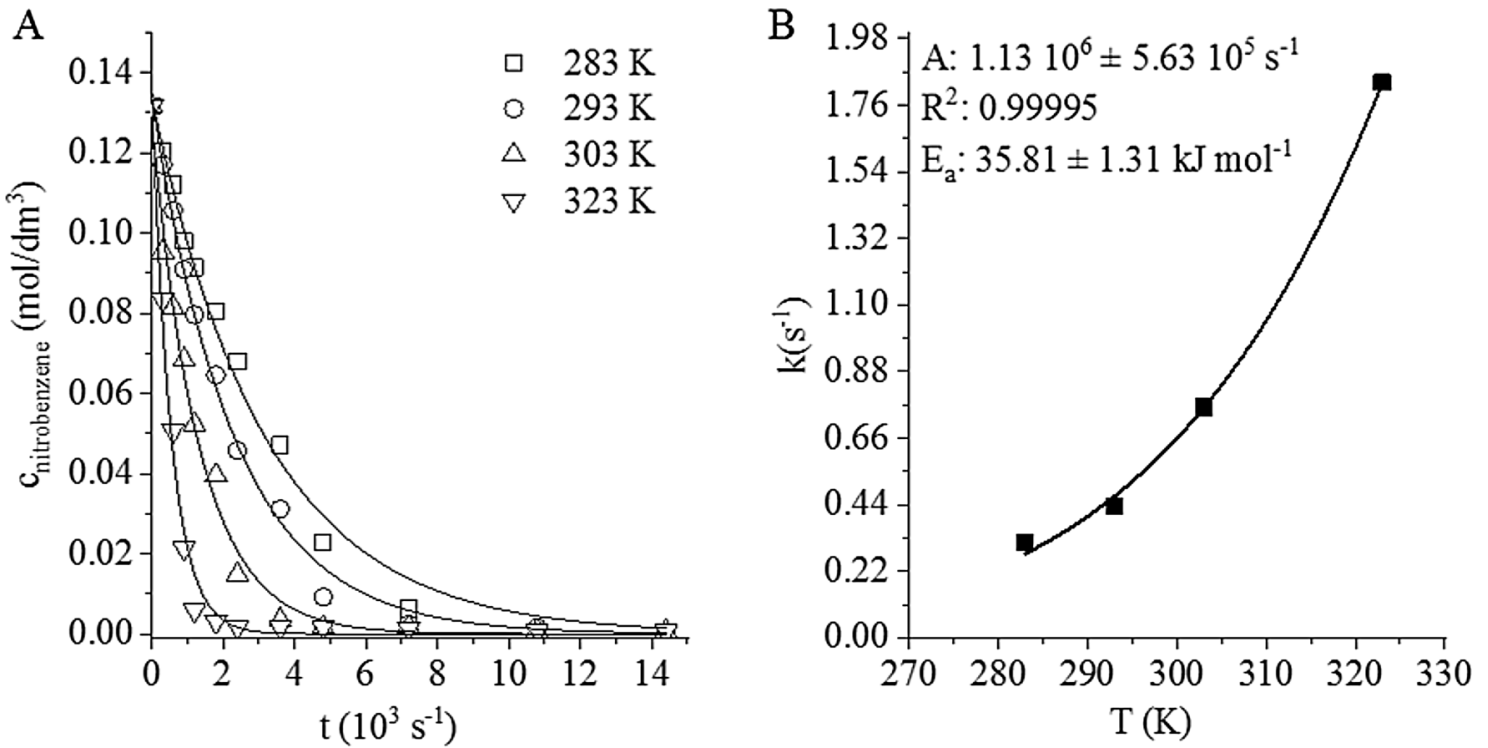

Fig. 8 Nitrobenzene concentration vs time of hydrogenation (a), and Arrhenius plot, $\mathrm{k} v s$ temperature (b)

the surface of the N-BCNT support. Thus, Pd/N-BCNT catalyst can be achieved in a one-step process.

Further activation was not necessary as the catalytic system was applicable in nitrobenzene hydrogenation. During the catalyst preparation, the N-BCNTs were oxidised and the formation of new oxygen containing groups confirmed the oxidation process. The deposited palladium and palladium-oxide nanoparticles are smaller than $5 \mathrm{~nm}$ based on HRTEM pictures. Despite the high palladium-oxide ratio the synthesized Pd/N-BCNT catalyst was highly active in nitrobenzene hydrogenation as the conversion was $98 \%$ at $323 \mathrm{~K}$ after $40 \mathrm{~min}$. Only one by-product ( $N$-methylaniline) 
in small quantities $\left(8 \mathrm{mmol} / \mathrm{dm}^{3}\right)$ was formed at higher temperature values. The activation energy was $35.81 \mathrm{~kJ} / \mathrm{mol}$, and it is similar to other works which indicates that the one-step procedure is applicable for catalyst preparation. All in all, the $\mathrm{Pd} / \mathrm{N}-\mathrm{BCNT}$ catalyst was successfully produced by using a one-step sonochemical method, where further activation was not necessary as the catalytic system was applicable in nitrobenzene hydrogenation.

Acknowledgements Open access funding provided by University of Miskolc (ME). This research was supported by the European Union and the Hungarian State, co-financed by the European Regional Development Fund in the framework of the GINOP-2.3.4-15-2016-00004 project, aimed to promote the cooperation between the higher education and the industry. The EFOP-3.6.1-16-2016-00014 project is also gratefully acknowledged for providing additional funding.

\section{Compliance with Ethical Standards}

Conflict of interest On behalf of all authors, the corresponding author states that there is no conflict of interest.

Open Access This article is licensed under a Creative Commons Attribution 4.0 International License, which permits use, sharing, adaptation, distribution and reproduction in any medium or format, as long as you give appropriate credit to the original author(s) and the source, provide a link to the Creative Commons licence, and indicate if changes were made. The images or other third party material in this article are included in the article's Creative Commons licence, unless indicated otherwise in a credit line to the material. If material is not included in the article's Creative Commons licence and your intended use is not permitted by statutory regulation or exceeds the permitted use, you will need to obtain permission directly from the copyright holder. To view a copy of this licence, visit https://creativecommons.org/licenses/by/4.0/.

\section{References}

1. Wegener G, Brandt M, Duda L et al (2001) Trends in industrial catalysis in the polyurethane industry. Appl Catal A 221:303-335. https://doi.org/10.1016/S0926-860X(01)00910-3

2. Ono Y, Ishida H (1981) Amination of phenols with ammonia over palladium supported on alumina. J Catal 72:121-128

3. Srikanth CS, Kumar VP, Viswanadham B et al (2015) Vapor phase hydrogenation of nitrobenzene to aniline over carbon supported ruthenium catalysts. J Nanosci Nanotechnol 15:5403-5409. https ://doi.org/10.1166/jnn.2015.9872

4. Collins DJ, Smith AD, Davis BH (1982) Hydrogenation of nitrobenzene over a nickel boride catalyst. Ind Eng Chem Prod Res Dev 21:279-281. https://doi.org/10.1021/i300006a016

5. Hatziantoniou V, Andersson B, Schoon NH (1986) Mass transfer and selectivity in liquid-phase hydrogenation of nitro compounds in a monolithic catalyst reactor with segmented gas-liquid flow. Ind Eng Chem Process Des Dev 25:964-970. https://doi. org/10.1021/i200035a021

6. Zhao F, Zhang R, Chatterjee M et al (2004) Hydrogenation of nitrobenzene with supported transition metal catalysts in supercritical carbon dioxide. Adv Synth Catal 346:661-668. https://doi. org/10.1002/adsc.200303230

7. Yan Y, Miao J, Yang Z et al (2015) Carbon nanotube catalysts: recent advances in synthesis, characterization and applications.
Chem Soc Rev 44:3295-3346. https://doi.org/10.1039/C4CS0 0492B

8. Serp P, Corrias M, Kalck P (2003) Carbon nanotubes and nanofibers in catalysis. Appl Catal A Gen 253:337-358. https://doi. org/10.1016/S0926-860X(03)00549-0

9. Guo X, Dong H, Li B et al (2017) Influence of the functional groups of multiwalled carbon nanotubes on performance of $\mathrm{Ru}$ catalysts in sorbitol hydrogenolysis to glycols. J Mol Catal A 426:79-87. https://doi.org/10.1016/J.MOLCATA.2016.11.003

10. Liao H-G, Xiao Y-J, Zhang H-K et al (2012) Hydrogenation of nitrocyclohexane to cyclohexanone oxime over Pd/CNT catalyst under mild conditions. Catal Commun 19:80-84. https://doi. org/10.1016/J.CATCOM.2011.12.027

11. Ratso S, Kruusenberg I, Joost U et al (2016) Enhanced oxygen reduction reaction activity of nitrogen-doped graphene/ multi-walled carbon nanotube catalysts in alkaline media. Int $\mathrm{J}$ Hydrog Energy 41:22510-22519. https://doi.org/10.1016/j.jihyd ene.2016.02.021

12. Sun Y, Chen L, Bao Y et al (2018) Roles of nitrogen species on nitrogen-doped CNTs supported $\mathrm{Cu}-\mathrm{ZrO} 2$ system for carbon dioxide hydrogenation to methanol. Catal Today 307:212-223. https://doi.org/10.1016/J.CATTOD.2017.04.017

13. Liu R, Liu R, Ma X et al (2018) Efficient diesel production over the iron-based Fischer-Tropsch catalyst supported on CNTs treated by urea/NaOH. Fuel 211:827-836. https://doi. org/10.1016/j.fuel.2017.09.114

14. Li C-H, Yu Z-X, Yao K-F et al (2005) Nitrobenzene hydrogenation with carbon nanotube-supported platinum catalyst under mild conditions. J Mol Catal A Chem 226:101-105. https://doi. org/10.1016/j.molcata.2004.09.046

15. Dong B, Li Y, Ning X et al (2017) Trace iron impurities deactivate palladium supported on nitrogen-doped carbon nanotubes for nitrobenzene hydrogenation. Appl Catal A 545:54-63. https://doi. org/10.1016/J.APCATA.2017.07.035

16. Hao L, Li H, Hu Y et al (2014) Carbon nanotube-supported bimetallic Pt-Fe catalysts for nitrobenzene hydrogenation. Micro Nano Lett 9:97-99. https://doi.org/10.1049/mnl.2013.0624

17. Zhao F, Ikushima Y, Arai M (2004) Hydrogenation of nitrobenzene with supported platinum catalysts in supercritical carbon dioxide: effects of pressure, solvent, and metal particle size. J Catal 224:479-483. https://doi.org/10.1016/j.jcat.2004.01.003

18. Fujisawa K, Tojo T, Muramatsu H et al (2011) Enhanced electrical conductivities of $\mathrm{N}$-doped carbon nanotubes by controlled heat treatment. Nanoscale 3:4359. https://doi.org/10.1039/c1nr10717h

19. Vanyorek L, Muranszky G, Sikora E et al (2019) Synthesis optimization and characterization of nitrogen-doped bamboo-shaped carbon nanotubes. J Nanosci Nanotechnol 19:429-435. https:// doi.org/10.1166/jnn.2019.15776

20. Yang Y, Lan G, Wang X, Li Y (2016) Direct synthesis of nitrogen-doped mesoporous carbons for acetylene hydrochlorination. Chin J Catal 37:1242-1248. https://doi.org/10.1016/S1872 $-2067(16) 62459-2$

21. Paraknowitsch JP, Thomas A (2013) Doping carbons beyond nitrogen: an overview of advanced heteroatom doped carbons with boron, sulphur and phosphorus for energy applications. Energy Environ Sci 6:2839. https://doi.org/10.1039/c3ee41444b

22. Suslick K (1998) Kirk-Othmer encyclopedia of chemical technology, 4th edn. J. Wiley, New York

23. Qiu X-F, Zhu J-J, Chen H-Y (2003) Controllable synthesis of nanocrystalline gold assembled whiskery structures via sonochemical route. J Cryst Growth 257:378-383. https://doi. org/10.1016/S0022-0248(03)01467-2

24. Yu Ying;Zhang Qi-Yun;Li Xing-Guo (2003) Reduction Process of Transition Metal Ions by Zinc Powder to Prepare Transition Metal Nanopowder. Acta Phys Chim Sin 19:436-440. https://doi. org/10.3866/PKU.WHXB20030512 
25. Qiu X-F, Zhu J-J (2003) Synthesis of palladium nanoparticles by a sonochemical method. Chin J Inorg Chem 19:766-770

26. Wu S-H, Chen D-H (2003) Synthesis and characterization of nickel nanoparticles by hydrazine reduction in ethylene glycol. J Colloid Interface Sci 259:282-286. https://doi.org/10.1016/S0021 -9797(02)00135-2

27. Kan C, Cai W, Li C et al (2003) Ultrasonic synthesis and optical properties of $\mathrm{Au} / \mathrm{Pd}$ bimetallic nanoparticles in ethylene glycol. J Phys D Appl Phys 36:1609-1614. https://doi. org/10.1088/0022-3727/36/13/328

28. Li Q, Li H, Pol VG et al (2003) Sonochemical synthesis, structural and magnetic properties of air-stable Fe/Co alloy nanoparticles. N J Chem 27:1194. https://doi.org/10.1039/b302136j

29. Höller V, Wegricht D, Yuranov I et al (2000) Three-phase nitrobenzene hydrogenation over supported glass fiber catalysts: reaction kinetics study. Chem Eng Technol 23:251-255. https:// doi.org/10.1002/(SICI) 1521-4125(200003)23:3\%3c251:AIDCEAT251\%3e3.0.CO;2-S

30. Klemm E, Amon B, Redlingshöfer H et al (2001) Deactivation kinetics in the hydrogenation of nitrobenzene to aniline on the basis of a coke formation kinetics-investigations in an isothermal catalytic wall reactor. Chem Eng Sci 56:1347-1353. https://doi. org/10.1016/S0009-2509(00)00357-2

31. Yao H-C, Emmett PH (1961) Kinetics of liquid phase hydrogenation. II. Hydrogenation of aromatic and aliphatic nitrocompounds over a colloidal platinum catalyst. J Am Chem Soc 83:796-799. https://doi.org/10.1021/ja01465a011

32. Fuentes J, Clarke M (2008) Deoxygenation of pyridine $N$-oxides by palladium-catalysed transferoxidation of trialkylamines. Synlett 2008:2579-2582. https://doi.org/10.1055/s-0028-1083508

33. Aruna I, Mehta BR, Malhotra LK, Shivaprasad SM (2008) Size dependence of core and valence binding energies in Pd nanoparticles: Interplay of quantum confinement and coordination reduction. J Appl Phys 104:064308. https://doi.org/10.1063/1.2973682
34. Boronin AI, Slavinskaya EM, Danilova IG et al (2009) Investigation of palladium interaction with cerium oxide and its state in catalysts for low-temperature CO oxidation. Catal Today 144:201211. https://doi.org/10.1016/j.cattod.2009.01.035

35. Yue C, Wang J, Han L et al (2015) Effects of pretreatment of Pd/ $\mathrm{AC}$ sorbents on the removal of $\mathrm{Hg} 0$ from coal derived fuel gas. Fuel Process Technol 135:125-132. https://doi.org/10.1016/J. FUPROC.2014.11.038

36. Wang C, Yang F, Yang W, Ren L, Zhang Y, Jia X, Zhang L, Li Y (2012) PdO nanoparticles enhancing the catalytic activity of $\mathrm{Pd} /$ carbon nanotubes for 4-nitrophenol reduction. RSC Adv 5:27526-27532

37. Lente G (2015) Deterministic kinetics in chemistry and systems biology. Springer International Publishing, Cham

38. Qu R, Macino M, Iqbal S et al (2018) Supported Bimetallic AuPd Nanoparticles as a Catalyst for the Selective Hydrogenation of Nitroarenes. Nanomaterials 8:690. https://doi.org/10.3390/nano8 090690

39. Peureux J, Torres M, Mozzanega H et al (1995) Nitrobenzene liquid-phase hydrogenation in a membrane reactor. Catal Today 25:409-415. https://doi.org/10.1016/0920-5861(95)00128-3

40. Easterday R, Sanchez-Felix O, Losovyj Y et al (2015) Design of ruthenium/iron oxide nanoparticle mixtures for hydrogenation of nitrobenzene. Catal Sci Technol 5:1902-1910. https://doi. org/10.1039/C4CY01277A

41. Turáková M, Salmi T, Eränen K et al (2015) Liquid phase hydrogenation of nitrobenzene. Appl Catal A 499:66-76. https://doi. org/10.1016/j.apcata.2015.04.002

Publisher's Note Springer Nature remains neutral with regard to jurisdictional claims in published maps and institutional affiliations.

\section{Affiliations}

\section{Ádám Prekob ${ }^{1}$ - Gábor Muránszky ${ }^{1}$. István Kocserha ${ }^{2} \cdot$ Béla Fiser $^{1,3} \cdot$ Ferenc Kristály $^{4} \cdot$ Gyula Halasi $^{5} \cdot$ Zoltán Kónya $^{5}$. Béla Viskolcz ${ }^{1} \cdot$ László Vanyorek $^{1}$}

Ádám Prekob

kempadam@uni-miskolc.hu

Gábor Muránszky

kemmug@uni-miskolc.hu

István Kocserha

istvan.kocserha@uni-miskolc.hu

Béla Fiser

fiser.bela@gmail.com

Ferenc Kristály

askkf@uni-miskolc.hu

Gyula Halasi

halasigy@chem.u-szeged.hu

Zoltán Kónya

konya@ chem.u-szeged.hu
Béla Viskolcz

bela.viskolcz@uni-miskolc.hu

1 Institute of Chemistry, University of Miskolc, Miskolc-Egyetemváros 3515, Hungary

2 Institute of Ceramic and Polymer Engineering, University of Miskolc, Miskolc Egyetemváros 3515, Hungary

3 Ferenc Rákóczi II. Transcarpathian Hungarian Institute, Beregszász, Transcarpathia 90200, Ukraine

4 Institute of Mineralogy and Geology, University of Miskolc, 3515 Miskolc-Egyetemváros, Hungary

5 Department of Applied and Environmental Chemistry, University of Szeged, Szeged, Rerrich Béla tér 1, 6720, Hungary 